\title{
Intramolecular control of excited state electron and energy electron transfer
}

\author{
Thomas J. Meyer \\ Department of Chemistry, The University of North Carolina, Chapel Hill, North \\ Carolina 27599 USA

\begin{abstract}
Polypyridyl complexes of $\operatorname{Ru}(I I), 0 s(I I)$, and $\operatorname{Re}(I)$ absorb visible light through metal to ligand charge transfer (MLCT) transitions. Molecular assemblies have been designed incorporating the excited states to allow study of intramolecular electron and energy transfer processes.
\end{abstract}

\section{INTRODUCTION}

The study of photochemistry has been greatly enriched by polypyridyl complexes of Ru(II) and Os(II). Although these complexes have been known for some time to be visible light emitters, most of the interest in their excited states has come from a recognition of their electron transfer properties. The combination of visible light absorptivity and excited state electron transfer has led to many fundamental studies and to a variety of photoconversion schemes based on initial excitation and electron transfer quenching (refs. $1-3$ ).

In this account I will summarlze the efforts of my group to understand and exploit light induced, intramolecular electron and energy transfer based on polypyridyl complexes of $\mathrm{Ru}(I I)$, Os(II), and $\operatorname{Re}(I)$. Before surveying our results, it is of value to summarize what is known about the basic photochemical and photophysical properties of these complexes.

\section{METAL TO LIGAND CHARGE TRANSFER (MLCT) PHOTOCHEMISTRY}

Although polypyridyl complexes such as $\left[R u(b p y)_{3}\right]^{2+}$ (bpy is $2,2^{\prime}$-bipyridine) are relatively large, complex molecules, much has been learned about their photochemistry and photophysics by a combination of spectroscopic and time resolved emission and absorption measurements (ref. 1). These complexes characteristically absorb light in the visible region. The origin of the visible light absorptivity lies in a series of metal to ligand charge transfer (MLCT) transitions involving excitation from the $\left(\mathrm{d}_{\pi}\right)^{6}$ core at the metal to lowlying $\pi^{*}$ acceptor levels on the polypyridyl ligands, eq. (1).

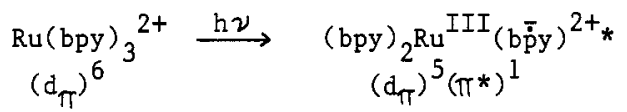

In fluid solution the electron resides on one of the three bpy ligands but, no doubt, undergoes rapid intramolecular transfer among them.

The electronic structures of these complexes are complicated (refs. 4,5). There are a series of MLCT transitions because the lower than ${ }_{0}$ symmetry at the metal splits the $d \pi$ levels and a series of $\pi^{*}$ acceptor levels exist at the ligands. In addition, excited states of $\pi *$ and dd orbital origins exist at energies which are comparable to those of the MLCT states in the excited state manifolds. By making varjations in metal and ligand the lowest excited state can be tuned from dd, e.g., $\left[\mathrm{Fe}(\mathrm{bpy})_{3}\right]^{2{ }^{2}}$, to $\pi^{*}, \mathrm{e}_{\mathrm{g} .,}\left[\mathrm{Rh}(\mathrm{bpy})_{3}\right]^{3+}$. For complexes of $\operatorname{Ru}(I I), 0 s(I I)$, or $\operatorname{Re}(I)$, the visible absorptivity is usually dominated by MLCT transitions to excited states that are largely singlet in character, $\left(d_{\pi}\right)^{b} \stackrel{h \nu}{\longrightarrow}{ }^{1}\left[\left(d_{\pi}\right)^{5}\left(\pi^{*}\right)^{1}\right]$.

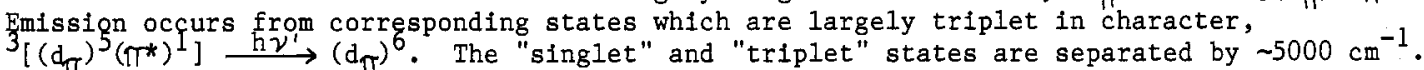
They are not pure spin states but are extensively mixed by spin-orbit coupling.

The decay of MLCT excited states in fluid solution is typically dominated by nonradiative processes. In nonradiative decay, the excess energy that is released in the excited to ground state electronic transition must appear in the surrounding vibrations and in the solvent. From spectroscopic measurements the energy released appears largely in seven $\nu$ (bpy) ring stretching modes with lesser roles played by low frequency metal-1igand modes and the solvent (ref. 6). By comparing nonradiative rate constants for related families of complexes such as $\left[(\text { bpy }) \mathrm{Os}_{\mathrm{s}}(\mathrm{I})_{4}\right]^{2+}\left(\mathrm{L}=\mathrm{py}, \mathrm{PR}_{3}, \mathrm{CH}_{3} \mathrm{CN}, \ldots\right)$, it has been found that nonradiative decay follows the qualitative energy gap law in eq. (2). 


$$
\operatorname{lnk}_{\mathrm{nr}} \propto \frac{\gamma E}{\mathrm{~h} \omega}
$$

In eq. (2), $E$ is the energy gap between the excited and ground states, $\hbar \omega=h \nu$ is an averaged vibrational spacing for the bipy based ring stretching modes, and $=\ln (\mathrm{E} / \mathrm{S} \hbar \omega)-1$. The quantity $S$ is the electron-vibrational coupling constant; it is proportional to the square of the change in equilibrium displacement in the averaged $\nu$ (bpy) mode between the ground and excited states.

\section{LIGHT INDUCED ELECTRON AND ENERGY TRANSFER}

Light absorption occurs with the promotion of an electron to a higher level, e.g., eq. (1). The resulting excited state has both enhanced oxidizing and reducing properties compared with the ground state. This is especially clear for an MLCT excited state such as [Ru(bpy) $\left.{ }_{3}\right]^{2+_{*}}$ given the combined oxidized-metal, radical-anion orbital character of the excited state. Kinetic quenching and spectroscopic techniques have been utilized to estimate reduction potentials for MLCT excited states. The results for $\left[\mathrm{Ru}(\mathrm{bpy})_{3}\right]^{2+}{ }_{*}$ in $\mathrm{CH}_{3} \mathrm{CN}$ are summarized in the Latimer-type diagram shown in Fig. 1.

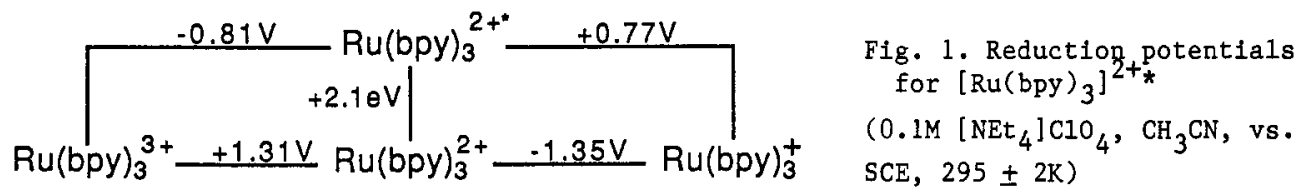

MLCT excited states characteristically undergo facile electron transfer as shown by the examples of oxidative and reductive quenching in reactions (3) (ref. 8) and (4) (ref. 9).

$$
\begin{aligned}
& \mathrm{Ru}(\mathrm{bpy})_{3}{ }^{2+} *+\mathrm{PQ}^{2+} \rightarrow \mathrm{Ru}(\mathrm{bpy})_{3}{ }^{3+}+\mathrm{PQ}^{+} \\
& \mathrm{Ru}(\mathrm{bpy})_{3}{ }^{2+}+\mathrm{Me}_{2} \mathrm{NPh} \rightarrow \mathrm{Ru}(\mathrm{bpy})_{3}{ }^{3+}+\mathrm{Me}_{2} \mathrm{NPh}^{+}
\end{aligned}
$$

Electron transfer is rapid, one reason being that the complexes are large which minimizes the solvent regrganizational barrier. A second reason is that the structural differences between $\left[\mathrm{Ru}(\mathrm{bpy})_{3}\right]^{2{ }_{*}}$ and 1 ts reduced, $\left[\mathrm{Ru}(\mathrm{bpy})_{3}\right]^{+}$, or oxidized, [Ru(bpy $\left.)_{3}\right]^{3+}$, neighbours are slight, which minimizes the inner-sphere reorganizational barrier to electron transfer.

By photolyzing solutions which contain both an electron transfer acceptor and a donor, it is possible to utilize coupled electron transfer reactions, such as those shown in Scheme 1 , to convert the initial energy of the excited state into a transiently stored redox energy (ref. $10)$.

Scheme 1

$$
\begin{aligned}
& \mathrm{Ru}(\mathrm{bpy})_{3}{ }^{2+} \stackrel{\mathrm{h} \nu}{\longrightarrow} \mathrm{Ru}(\mathrm{bpy})_{3}{ }^{2+} \\
& \mathrm{Ru}(\mathrm{bpy})_{3}{ }^{2+}+\mathrm{PQ}^{2+} \longrightarrow \mathrm{Ru}(\mathrm{bpy})_{3}{ }^{3+}+\mathrm{PQ}^{+} \\
& \mathrm{Ru(bpy)}{ }^{3+}+\mathrm{Me}_{2}{ }^{\mathrm{NPh}} \rightarrow \mathrm{Ru}(\mathrm{bpy})_{3}{ }^{2+}+\mathrm{Me}_{2} \mathrm{NPh}^{+} \\
& \mathrm{PQ}^{2+}+\mathrm{Me}_{2} \mathrm{NPh} \stackrel{\mathrm{h} \nu}{\longrightarrow} \mathrm{PQ}^{+}+\mathrm{Me}_{2} \mathrm{NPh}^{+}
\end{aligned}
$$

Just as barriers to electron transfer are low and electron-transfer rate constants high, MLCT excited states undergo facile energy transfer quenching by a variety of organic or transition metal complex acceptors, e.g., reaction (5) where An is anthracene (refs. 11,12).

$$
\mathrm{Ru}(\mathrm{bpy})_{3}{ }^{2+} *+\mathrm{An} \rightarrow \mathrm{Ru}(\mathrm{bpy})_{3}{ }^{2+}+{ }^{3} \mathrm{An}
$$

Energy transfer is facile because the structural differences between the ground and excited states are relatively small. In addition, the mixed spin character of the excited states provides them, at least in theory, with the ability to undergo energy transfer by either troplet (exchange) energy transfer or Forster singlet energy transfer.

\section{INTRAMOLECULAR CONTROL OF LIGHT INDUCED ELECTRON AND ENERGY TRANSFER}

Much of our recent work on MLCT excited states has been directed toward incorporating the excited states into molecular assemblies in order to study intramolecular light induced 
electron and energy transfer processes. There are several goals to this work. One is to utilize well defined MLCT excited states to explore the fundamental details of how electron and energy transfer occur. Another is to learn how to prepare molecular assemblies in which long range energy or electron transfer can occur and, in so doing, to mimic, for example, the reaction centre in photosynthesis. Still another is to prepare assemblies which can act as interfaces between simple excited state electron transfer and the multielectron catalysts that are required to carry out such small molecule redox reactions as the oxidation of water to $\mathrm{O}_{2}$ or the reduction of $\mathrm{CO}_{2}$. Finally, we hope to be able to translate the solution based photochemistry to polymeric films where it may be possible to utilize molecular level photochemistry in device-like applications.

\section{Electron transfer}

One of our initial goals was to reconstruct the excited state quenching scheme in reactions (3) or (4) intramolecularly by attaching the quenchers directly to the chromophore. As our infitial choice for an electron transfer acceptor we turned to the alkylated pyridinium, MQ ${ }^{+}$, which is a close relative of $\mathrm{PQ}^{2+}$ and prepared the complexes $\left[\mathrm{Ru}(\mathrm{bpy})_{2}\left(\mathrm{MQ}^{+}\right)_{2}\right]^{4+}$ (ref. 13), $\left[\mathrm{Os}(\mathrm{bpy})_{2}(\mathrm{CO})\left(\mathrm{MQ}^{+}\right)\right]^{3+}$ and $\left[\operatorname{Re}(\mathrm{bpy})(\mathrm{CO})_{3}\left(\mathrm{MQ}^{+}\right)\right]^{2+}$ (ref. 14). In all three cases, direct experimental evidence has been found for intramolecular electron transfer following initial MLCT excitation. The $\operatorname{Re}(I)$ complex has been studied in the greatest detall, and the sequence of events that occurs following $\operatorname{Re}$ bpy excltation is shown in Scheme 2 (ref. 15).

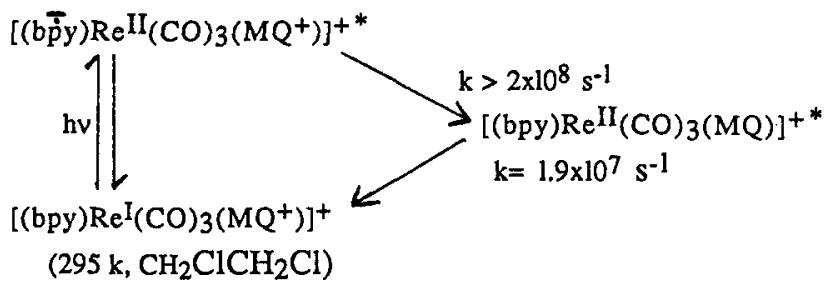

\section{Scheme 2}

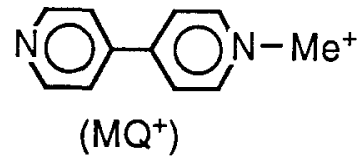

There are some interesting nuances to this system. The $\mathrm{MQ}^{+}$based state that is formed as a consequence of bpy $\longrightarrow \mathrm{MQ}^{+}$Intramolecular electron transfer is a lower energy MLCT excited state of the system and is a weak emitter. There is a considerable change in structure at the $\mathrm{MQ}^{+}$ligand between the ground and excited states. The angle between the pyridyl rings apparently changes from $\sim 45^{\circ}$ in the ground state to a nearly coplanar structure with $\theta \sim 0^{\circ}$ in the excited state (ref. 16). Intramolecular electron transfer does not occur in solvent glasses at low temperature because the surrounding solvent dipoles are frozen and can not reorient (ref. 17). Howepver, in the derivative $\left[\left(4,4^{\prime}-\left(\mathrm{NH}_{2}\right) 2_{2} \text { bpy) } \operatorname{Re}(\mathrm{CO}) 3_{3}\left(\mathrm{MQ}^{+}\right)\right]^{+},-\Delta G\right.$ for $\left(4,4^{\circ}-\left(\mathrm{NH}_{2}\right) 2^{-b p y}\right) \longrightarrow \mathrm{MQ}^{+}$electron transfer is increased to $1.0 \mathrm{eV}$. Electron transfer does occur in low temperature glasses for this complex because it occurs in the Marcus "inverted region".

For reductive quenching we have turned to derivatives of dimethylaniline and phenothiazine.
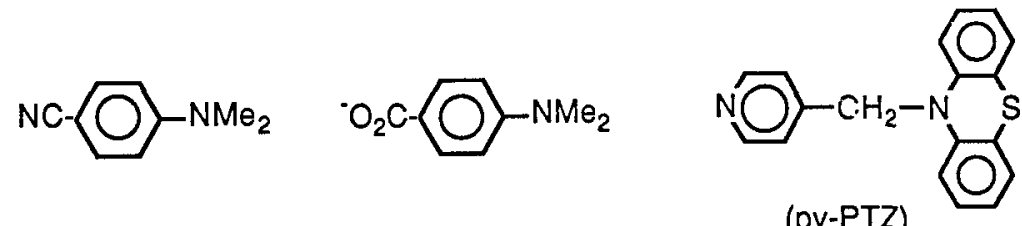

(py-PTZ)

Complexes such as $\left[0 \mathrm{Os}(\mathrm{bpy})_{2}(\mathrm{CO})\left(\mathrm{p}-\mathrm{O}_{2} \mathrm{CC}_{6} \mathrm{H}_{4} \mathrm{NMe}_{2}\right)\right]^{+}$or $\left[\operatorname{Re}(\mathrm{bpy})(\mathrm{CO})_{3}(\mathrm{py}-\mathrm{PTZ})\right]^{+}$have been prepared. The photophysical properties of the Re complex have been investigated in detail by transient absorbance and emission experiments. These studies have revealed that the sequence of events shown in Scheme 3 occurs following $\operatorname{Re} \longrightarrow$ bpy excitation (ref. 18).

\section{Scheme 3}

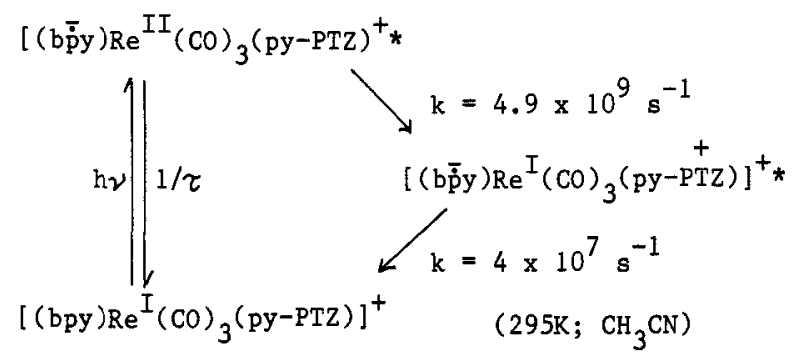


In this case, MLCT exciţation leads to the appearance of the "redox separated" state, $\left[\left(\mathrm{b} \mathrm{p}^{\frac{1}{\mathrm{y}}}\right) \operatorname{Re}(\mathrm{CO}){ }_{3}(\mathrm{py}-\mathrm{PIZ})\right]^{+}$, rapidly and with high efficiency.

Because of the straightforward nature of the synthetic chemistry, we have been able to prepare a family of related complexes, $\left[\left(4,4^{\prime}-(\mathrm{X})_{2}-\mathrm{bpy}\right) \operatorname{Re}(\mathrm{CO})_{3}(\mathrm{py}-\mathrm{PTZ})\right]^{+}\left(\mathrm{X}=\mathrm{OMe}, \mathrm{H}, \mathrm{C}_{6} \mathrm{H}_{5}\right.$, $\mathrm{CO}_{2} \mathrm{CH}_{3}, \ldots$ ), where substituent changes have been made at the $4,4^{\prime}-$ positions of the bpy 1igand. The substituents vary from electron donating (e.g., $-\mathrm{OCH}_{3}$ ) to electron withdrawing $\left(\mathrm{e} . \mathrm{g} .,-\mathrm{CO}_{2} \mathrm{CH}_{3}\right)$. Through their effects on the $\pi^{*}$ levels of the bpy ligands it is possible to vary $\Delta G$ for the back, intramolecular electron transfer in reaction (6) from 1.4 to $2.1 \mathrm{eV}$.

$$
\left[\left(4,4^{\prime}-(\mathrm{X})_{2}-\mathrm{b} \overline{\mathrm{p} y}\right) \operatorname{Re}(\mathrm{CO})_{3}\left(\mathrm{py}-\mathrm{PTZ}^{+}\right)\right]^{+}-->\left[\left(4,4^{\prime}-(\mathrm{X})_{2}-\mathrm{bpy}\right) \operatorname{Re}(\mathrm{CO})_{3}(\mathrm{py}-\mathrm{PTZ})\right]^{+}
$$

These reactions are well into the Marcus "inverted" region. As predicted theoretically, their rate constants decrease as $\Delta G$ becomes more favourable with $\ln (k)$ varying linearly with $-\Delta G$ as predicted by the energy gap law for nonradiative decay (ref. 19).

The synthetic chemistry is also available for preparing complexes in which there are both chemically attached electron transfer donors and acceptors, e.g., [(bpy-PTZ) $\left.\operatorname{Re}(\mathrm{CO}){ }_{3}\left(\mathrm{MQ}^{\dagger}\right)\right]{ }^{2+}$.

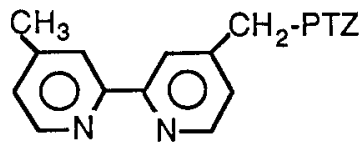

(bpy-PTZ)

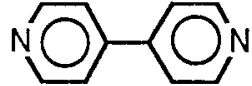

$\left(4,4^{\prime}-\right.$ bpy $)$

The complex of this kind that has been studied in most detail is illustrated in Fig. 2.

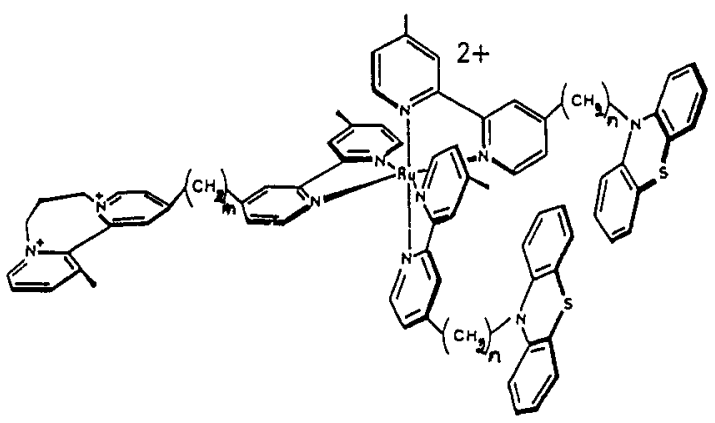

Fig. 2

In this case, initial excitation at the $\mathrm{Ru}^{\mathrm{II}} \longrightarrow$ bpy chromophore is followed by oxidative quenching by the bipyridinium oxidant and then by PTZ $\rightarrow$ Ru(III) electron transfer. The transient product is a redox separated state in which the excited electron resides on the bipyridinium site and the electron hole on PTZ (ref. 20).

Light induced intramolecular electron transfer has also been investigated in a series of ligand-bridged complexes. In the pfxed-valence complex,

$\left[\left(\mathrm{PhSCH}_{2} \mathrm{CH}_{2} \mathrm{SPh}\right)_{2} \mathrm{ClRu}^{\mathrm{II}}\left(4,4^{\prime}-\mathrm{bpy}\right) \mathrm{Ru}^{\mathrm{III}} \mathrm{Cl}(\mathrm{bpy})_{2}\right]^{3+}$, Ru $\mathrm{Ru}^{\rightarrow} \rightarrow 4^{\prime}$-bpy excitation does not simply

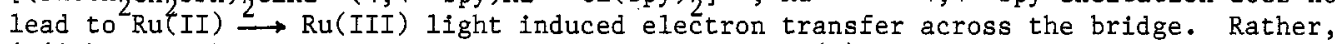
4,4'-bpy $\rightarrow$ bpy electron transfer occurs, reaction (7), as shown by the appearance of the characteristic $\mathrm{Ru}^{\mathrm{III}}$-bpy emission following $\mathrm{Ru}^{\mathrm{II}} \longrightarrow\left(4^{\prime}, 4^{\prime}\right.$-bpy) excitation (ref. 21 ).

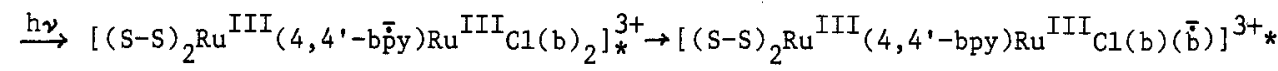

( $\mathrm{S}-\mathrm{S}$ is $\mathrm{PhSCH}_{2} \mathrm{CH}_{2} \mathrm{SPh}$; b is bpy)

In the ligand-bridged os complex, $\left[(\text { bpy })_{2}(\mathrm{CO}) 0 \mathrm{~s}^{\mathrm{II}}\left(4,4^{\prime}-\mathrm{bpy}\right) 0 \mathrm{~s}^{\mathrm{II}} \text { (phen) }\left(\mathrm{cis}-\mathrm{Ph}_{2} \mathrm{PCH}^{\mathrm{P}} \mathrm{CHPPh}_{2}\right)\right]^{3+}$, initial $\mathrm{Os}^{\mathrm{II}} \longrightarrow$ bpy excitation creates an excited state mixed-valence complex, reaction (8). $\left[(\mathrm{b}){ }_{2}(\mathrm{CO}) 0 \mathrm{~s}^{\mathrm{II}}\left(4,4^{\prime}-\mathrm{bpy}\right) 0 \mathrm{~s}^{\mathrm{II}} \mathrm{C} 1 \text { (phen) }(\mathrm{P}-\mathrm{P})\right]^{3+} \stackrel{\mathrm{h} \nu}{\longrightarrow}$

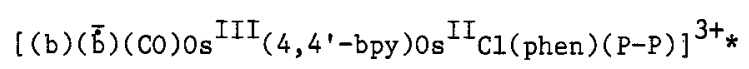

$\left(\mathrm{P}-\mathrm{P}\right.$ is cis $\left.-\mathrm{Ph}_{2} \mathrm{PCH}=\mathrm{CHPPh}_{2}\right)$

At low temperature in a frozen glass, inftial os $\rightarrow$ bpy excitation is followed by intramolecular transfer across the ligand bridge to give a remote MLCT excited state, reaction (9) (ref. 22).

$$
\begin{aligned}
& {\left[(\mathrm{b})(\bar{b})(\mathrm{CO}) 0 \mathrm{~s}^{\mathrm{III}}\left(4^{,} 4^{\prime}-\mathrm{bpy}\right) 0 \mathrm{~s}^{\mathrm{II}} \mathrm{CI}(\mathrm{phen})(\mathrm{P}-\mathrm{P})\right]^{3+} * \rightarrow} \\
& {\left[(\mathrm{b})(\bar{b})(\mathrm{CO}) 0 \mathrm{~s}^{\mathrm{II}}\left(4^{,} 4^{\prime} \text {-bpy }\right) 0 \mathrm{~s}^{\mathrm{III}} \mathrm{Cl} \text { (phen) }(\mathrm{P}-\mathrm{P})\right]^{3+} \text { * }}
\end{aligned}
$$


In the remote MLCT state, the exclted electron/electron hole pair is separated across the ligand bridge. At room temperature in fluid solution, subsequent bpy $\longrightarrow$ 4,4'-bpy electron transfer occurs to give the lowest fying, ligand-hridged based MLCT excited state of the

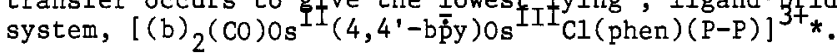

A related, $\mathrm{pH}$ dependent effect has been observed for the complex

$\left[(\mathrm{tpy})(\mathrm{bpy}) 0 \mathrm{~s}^{\mathrm{II}}\left(4,4^{\prime} \text {-bpy)Ru } \mathrm{Ru}^{\mathrm{II}}\left(\mathrm{H}_{2} \mathrm{O}\right)(\mathrm{bpy})_{2}\right]^{4+}\right.$ (tpy is $2,\left(2^{\prime}: 6^{\prime}\right), 2^{\prime \prime}$-terpyridine). An $0 s^{I I}-t p y$ based MLCT excited state is lowest lying in this complex. Either $0 s \rightarrow$ tpy or Ru $\rightarrow$ bpy excitation leads to this excited state with high efficiency, the latter by energy transfer across the bridge. However, in basic solution, past the $\mathrm{pK}_{\mathrm{a}}$ for the $\mathrm{Ru}^{\mathrm{II}}-\mathrm{OH}_{2}$ based acid at $\mathrm{pH} \sim 11, \mathrm{Os} \longrightarrow$ tpy excitation is followed by $\mathrm{Ru}^{\mathrm{II}}(\mathrm{OH}) \rightarrow \mathrm{Cs}^{\mathrm{III}}$ intramolecular electron transfer, which leads to reductive quenching of the $\mathrm{s}^{\text {III }}$-tpy excited state, reaction $(10)$ (ref. 23)

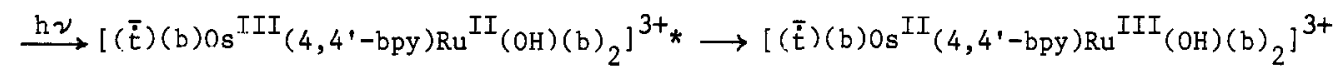

One of the goals of our work with ligand-bridged complexes is to learn how to achieve light induced redox splitting over long distances. In a recent experiment, the excitation-electron transfer sequence in reactions (8) and (9), which led to a remote MLCI state, has been extended by linking electron transfer donors or acceptors to the different sides of a complex across the ligand bridge. The complex prepared, [(bpy-PTZ) $\left.(\mathrm{CO}){ }_{3} \operatorname{Re}\left(4^{2}, 4^{\prime}-\mathrm{bpy}\right) \operatorname{Re}(\mathrm{CO}){ }_{3}(\mathrm{bpz})\right]^{27}$, was based on $\operatorname{Re}(I)$. In this complex, the bipyrazine ligand (bpz) has $\pi^{*}$ levels that are lower lying than the $\pi^{*}$ levels in bpy by $\sim 0.5 \mathrm{eV}$.

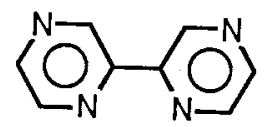

(bpz)

Either $\mathrm{Re} \longrightarrow$ bpy or $\mathrm{Re} \longrightarrow$ bpz excitation leads to the same net reaction, formation of the long-range, redox separated state in reaction (11). In either case, initial MLCT excitation is followed by a series of rapid electron transfer events which lead to light induced redox splitting across the ligand bridge with high efficiency (ref. 24).

$$
\begin{aligned}
{\left[(\mathrm{bpy}-\mathrm{PTZ})(\mathrm{CO}){ }_{3} \operatorname{Re}^{\mathrm{I}}\left(4,4^{\prime}-\mathrm{bpy}\right) \operatorname{Re}^{\mathrm{I}}(\mathrm{CO})_{3}(\mathrm{bpz})\right]^{2+} \stackrel{\mathrm{h \nu}}{\longrightarrow} } \\
\qquad\left[\left(\mathrm{bpy}-\mathrm{PTz}^{+}\right)(\mathrm{CO})_{3} \operatorname{Re}^{\left.\mathrm{I}\left(4,4^{\prime}-\mathrm{bpy}\right) \operatorname{Re}^{\mathrm{I}}(\mathrm{CO})_{3}\left(\mathrm{~b} \bar{p}^{-} z\right)\right]^{2+} *}\right.
\end{aligned}
$$

\section{Energy transfer}

Although less well developed in our work, the study of light induced intramolecular energy transfer based on MLCT excited states has also been profitable. In one set of experiments, the same tack was taken as in electron transfer quenching, in this case by adding an energy transfer acceptor $t q_{+}{ }^{a}$ MLCT chromophore by a chemical link. In the complex prepared, $\left[\mathrm{Ru}\left(\mathrm{bpyCH}_{2} \mathrm{OCH}_{2} \mathrm{An}\right)_{3}\right]^{2+}$, the energy transfer acceptor is an anthryl derivative.

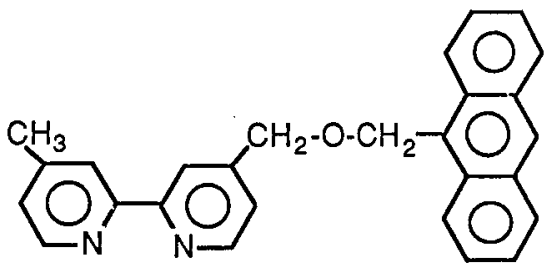

(bpyCH $\mathrm{CH}_{2} \mathrm{OCH}_{2} \mathrm{An}$ )

In this complex, $\mathrm{Ru} \longrightarrow$ bpy excitation is followed by rapid, $\mathrm{k}\left(295 \mathrm{~K}, \mathrm{CH}_{3} \mathrm{CN}\right)>5 \mathrm{x} 10^{8} \mathrm{~s}^{-1}$, intramolecular energy transfer to the anthryl group which gives the corresponding anthryl triplet, reaction (12) (ref. 25).

$$
\begin{aligned}
\stackrel{h \nu}{\longrightarrow} & {\left[(b-\mathrm{An}) 2_{2} \mathrm{Ru}^{\mathrm{III}}\left(\mathrm{b} \dot{\mathrm{p} y C H} \mathrm{OCH}_{2} \mathrm{An}\right)\right]^{2+} * \rightarrow\left[(\mathrm{b}-\mathrm{An}) 2^{\mathrm{Ru}^{\mathrm{II}}}\left(\mathrm{bpyCH}_{2} \mathrm{OCH}_{2}{ }^{3} \mathrm{An}\right)\right]^{2+} * } \\
& \left(\mathrm{~b}-\mathrm{An} \text { is bpyCH}{ }_{2} \mathrm{OCH}_{2} \mathrm{An}\right)
\end{aligned}
$$

The complex itself has some interesting characteristics. It combines the visible light absorptivity of the metal complex with the relatively long-lived character of the organic triplet.

The second energy transfer system that has been studied in some detall involves energy transfer across a ligand bridge by an electron/energy transfer "cascade" mechanism. In the study, advantage was taken of the synthetic chemistry based on the $\operatorname{Re}^{I}$ (bpy) complexes in 
order to prepare unsymmetrical ligand-bridged complexes where the asymmetry was created by substituent changes at the $4,4^{\prime}$-positions of bpy.

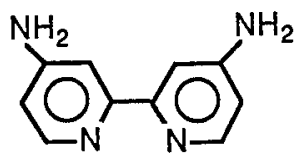

$\mathrm{b}\left(\mathrm{NH}_{2}\right)_{2}$

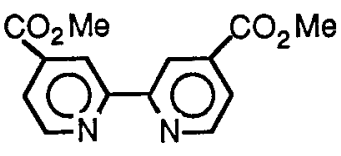

$\mathrm{b}\left(\mathrm{CO}_{2} \mathrm{Me}\right)_{2}$

In the 1igand-bridged complex, $\left[\left(\mathrm{b}\left(\mathrm{NH}_{2}\right)_{2}\right)(\mathrm{CO})_{3} \operatorname{Re}\left(4: 4^{\prime}-\mathrm{bpy}\right) \operatorname{Re}(\mathrm{CO})_{3}\left(\mathrm{~b}\left(\mathrm{CO}{ }_{2} \mathrm{Me}\right)_{2}\right]^{2+}\right.$, the effect of the electron donating $-\mathrm{NH}_{2}$ substituents is to raise the energy of the flCT states on one side, and the electron withdrawing $-\mathrm{CO}_{2} \mathrm{Me}$ substituents, to lower the energy on the other. Following $\mathrm{Re} \longrightarrow \mathrm{b}\left(\mathrm{NH}_{2}\right)_{2}$ excitation, spontaneous energy transfer occurs across the ligand bridge, reaction $(13)^{2}$ (ref. 26 ).

$$
\begin{aligned}
\stackrel{\mathrm{h} \nu}{\longrightarrow}\left[\left(\overline{\mathrm{B}}\left(\mathrm{NH}_{2}\right)_{2}\right)(\mathrm{CO})_{3} \operatorname{Re}^{\mathrm{II}}\left(4,4^{\prime}-\mathrm{bpy}\right) \mathrm{Re}^{\mathrm{I}}(\mathrm{CO})_{3}\left(\mathrm{~b}\left(\mathrm{CO}_{2} \mathrm{Me}\right)_{2}\right]^{2+} *\right. & \longrightarrow \\
& {\left[\left(\mathrm{b}\left(\mathrm{NH}_{2}\right)_{2}\right)(\mathrm{CO})_{3} \operatorname{Re}^{\mathrm{I}}\left(4,4^{\prime}-\mathrm{bpy}\right) \operatorname{Re}^{\mathrm{II}}(\mathrm{CO})_{3}\left(\overline{\mathrm{b}}\left(\mathrm{CO}{ }_{2} \mathrm{Me}\right)_{2}\right]^{2+} *\right.}
\end{aligned}
$$
However, the mechanism of energy transfer appears to involve initial $\mathrm{b}\left(\mathrm{NH}_{2}\right)_{2} \rightarrow 4^{\prime}, 4^{\prime}-$ bpy
electron transfer rather than direct energy transfer. Energy transfer can be blocked by placing methyl groups in the $3,3^{\prime}$ positions of the bridging ligand. The steric effect of the methyl groups prevents the two pyridyl rings of the bridging ligand from reaching coplanarity and it can not act as an electron transfer acceptor from $b\left(\mathrm{NH}_{2}\right)_{2}$.

\section{FINAL COMMENTS}

The study of light induced, intramolecular electron or energy transfer based on MLCT excited states is an area that is really only beginning. Future work will find extensions in a number of directions and, in the end, lead to exquisite control of excited state processes. More elaborate molecular assemblies will be constructed in order to achieve even longer range electron and energy transfer. The MLCT based systems will provide ideal families of complexes for studying the fundamental details of excited state energy or electron transfer processes. In time, appropriate tweaking of molecular properties will lead to the control of exotic processes such as wavelength dependent photochemistry, intramolecular time delays, and controlled, multiple photon processes. In the even longer term, these complex systems and the processes that can be constructed within them may provide an important basis for molecular level devices.

Acknowledgements are made to the National Science Foundation under grant no. CHE-8503092 for support of this research and to P. Chen, E. Danlelson, K. Schanze, S. Boyde, R. Duesing, G. Tapolsky and B. Loeb $L$. whose work I have abstracted in writing this article.

\section{REFERENCES}

1. a) G.A. Crosby, Acc. Chem. Res., 8, 231 (1975).

b) J. Ferguson, F. Herren, E.R. Rrausz, and J. Vrbanich, Coord. Chem. Rev., 64, 21 (1985).

c) T.J. Meyer, Pure Appl. Chem., 58, 1193 (1986).

2. a) V. Balzanf, F. Bolleta, M.T. Gandolfi, M. Maestri, Top. Curr. Chem., 75, 1 (1978).

b) K. Kalyanasundaram, Coord. Chem. Rev., 46, 159 (1982).

c) A. Juris, F. Barigelietti, S. Campagna, V. Balzani, P. Belser, A. von Zelewsky, Coord. Chem. Rev., 84, 85 (1988).

3. a) T.J. Meyer, Acc. Chem. Res., 11, 94 (1978); Prog. Inorg. Chem., 30, 389 (1983); Acc. Chem. Res., 22, 163 (1989).

b) N. Sutin and C. Creutz, Pure App1. Chem., 52, 2717 (1980).

c) V. Balzanf and F. Scandola, Energy resources Through Photochemistry and Catalysis: M. Gratzel, Ed.; Academic press: (1983).

d) Supramolecular Photochemistry: V. Balzani, Ed.; D. Reidel Pub. Co.; Dordrecht, Holland (1987).

4. a) E.M. Kober and T.J. Meyer, Inorg. Chem., 21, 3967 (1982); 22, 1614 (1983).

b) J. Ferguson and F. Herren, Chem. Phys., $7 \overline{6}, 45$ (1983).

5. a) S. Decurtins, F. Felix, J. Ferguson, H. U. Gude1, and A. Ludi, J. Am. Chem. Soc., 102, 4102 (1980).

b) H. Yersin and E. Gallhuber, J. Am. Chem. Soc., 106, 6582 (1984).

c) G. Hensler, E. Gallhuber, and H. Yersin, Inorg. Chem. 26, 1641 (1987); J. Am. Chem. Soc., 109,4814 (1987).

6. a) P.G. Bradley, N. Kress, B.A. Hornberger, R.F. Dallinger, and W.H. Woodruff, J. Am. Chem. Soc., 103, 7441 (1981).

b) J.V. Caspar, T.D. Westmoreland, G.H. Allen, P.G. Bradley, T.J. Meyer, W.H. Woodruff, J. Am. Chem. Soc., 106, 3492 (1984). 
7. a) E.M. Kober, J.V. Caspar, R.S. Lumpkin, and T.J. Meyer, J. Phys. Chem., 90, 3722 (1986).

b) J.V. Caspar, B.P. Sullivan, E.M. Kober, and T.J. Meyer, Chem. Phys. Lett., 91,91 (1982); J.V. Caspar and T.J. Meyer, J. Am. Chem. Soc., 105 , 5583 (1983).

8. a) H.D. Gafney and A.W. Adamson, J. Am. Chem. Soc, 94,8238 (1972); J.N. Demas and A.W. Adamson, J. Am. Chem. Soc., 95, 5159 (1973).

b) C.R. Bock, T.J. Meyer, and D.G. Whitten, J. Am. Chem. Soc., 96, 4710 (1974).

c) G. Navon and N. Sutin, Inorg. Chem., 13, 2159 (1974).

9. a) C.P. Anderson, D.J. Salmon, T.J. Meyer, and R.C. Young, J. Am. Chem. Soc., 99, 1980 (1977).

b) M. Maestri and M. Gratzel, Ber. Bunsen-Ges. Phys. Chem., 81, 504 (1977).

10. R.C. Young, T.J. Meyer, and D.G. Whitten, J. Am. Chem. Soc., 97,4781 (1975).

11. a) 0. Johansen, A.W.-H. Mau, and W.H.F. Sasse, Chem. Phys. Lett., 94, 113 (1983).

b) M. Wrighton and J. Markham, J. Phys. Chem., 77, 3042 (1973).

12. a) A.W.-H. Mau, O. Johansen, and W.H.F. Sasse, Photochem. Photobio1., 41, 503 (1985).

b) O. Johansen, A.W.-H. Mau, and W, H, F, Sasse, Chem. Phys. Lett., 94,107 (1983).

13. B.P. Sullivan, H. Abruna, H.O. Finklea, D.J. Salmon, J.K. Nagle, T.J. Meyer, and H. Sprintschnik, Chem. Phys. Lett., 58, 389 (1978).

14. T.D. Westmoreland, H. LeBozec, R. W. Murray, and T.J. Meyer, J. Am. Chem. Soc., 105,5952 (1983).

15. E. Danielson, H. LeBozec, P.Y. Chen, and T.J. Meyer, manuscript in preparation.

16. P.Y. Chen and T.J. Meyer, Inorg. Chem., in press.

17. P.Y. Chen, E. Danielson, and T.J. Meyer, J. Phys. Chem., 92, 3708 (1988).

18. a) T.D. Westmoreland, K.S. Schanze, P.E. Neveux, Jr., E. Danielson, B.P. Sullivan, P.Y. Chen, and T.J. Meyer, Inorg. Chem., 24, 2596 (1985).

b) P.Y. Chen, T.D. Westmoreland, K.S. Schanze, D. Athon, P.E. Neveux, Jr., and T.J. Meyer, Inorg. Chem., 26, 116 (1987).

19. R. Duesing, P.Y. Chen, G. Tapolsky, and T.J. Meyer, submitted.

20. E. Danielson, C.M. Elliott, J.W. Merkert, and T.J. Meyer, J. Am. Chem. Soc., 109,2519 (1987).

21. J.C. Curt1s, J.S. Bernste1n, and T.J. Meyer, Inorg. Chem., 24, 385 (1985).

22. K.S. Schanze, G.A. Neyhart, and T.J. Meyer, J. Phys. Chem., 90,2182 (1986).

23. B. Loeb L., G.A. Neyhart, L.A. Worl, E. Danielson, B.P. Sullivan, and T.J. Meyer, J. Phys. Chem., 93, 717 (1989).

24. R. Duesing, G. Tapolsky, and T.J. Meyer, submitted.

25. S. Boyde, G. Strouse, W.E. Jones, and T.J. Meyer, J. Am. Chem. Soc., in press.

26. G. Tapolsky, R. Duesing, and T.J. Meyer, J. Phys. Chem., 93, 3885 (1989). 